\title{
Cyclosporine-Associated Pericardial Tamponade in a Child with Steroid-Resistant Nephrotic Syndrome
}

\author{
S. Lalitha Rajalakshmi ${ }^{1}$ • Vaishnavi Raman ${ }^{1}$. Sudha Ekambaram ${ }^{1}$ (D) $\cdot$ Gnanasambandam Subramaniyam ${ }^{2}$. \\ N. C. Gowrishankar ${ }^{3}$ - B. R. Nammalwar ${ }^{1}$
}

Received: 23 December 2020 / Accepted: 18 March 2021 / Published online: 7 April 2021

(C) Dr. K C Chaudhuri Foundation 2021

To the Editor: Cyclosporine (CsA) is the preferred choice in steroid-resistant nephrotic syndrome (SRNS). A 2-y 10-moold boy with SRNS with minimal change histology, normal renal function and stage 2 hypertension was on prednisolone, CsA, enalapril and amlodipine. He developed respiratory distress $15 \mathrm{~d}$ after initiation of CsA (trough level $79 \mu \mathrm{g} / \mathrm{dL}$ ). Considering acute respiratory infection, CsA was withdrawn and treated with appropriate antibiotics. Echocardiogram showed moderate pericardial effusion (PE). His respiratory symptoms resolved with no change in PE. CsA was restarted on a higher dose and discharged.

$\mathrm{He}$ was brought $11 \mathrm{~d}$ later with cardiac tamponade. Emergency pericardiocentesis removed $250 \mathrm{~mL}$ of blood tinged fluid, which was transudative, sterile with inflammatory cytology and negative for tuberculosis (TB) by culture. He was euthyroid and antinuclear antibody (ANA) was negative. Post procedure echocardiogram revealed moderate PE. A positron emission tomography (PET) scan ruled out malignancy.

As isolated PE is rare in NS, ruling out secondary causes including infection, TB, lupus nephritis, malignancy, hypothyroidism and uremia, CsA-associated PE was considered by exclusion [1]. CsA causes PE by idiosyncrasy or hypersensitivity $[1,2]$. CsA was replaced with mycophenolate mofetil and echocardiograms on follow-up revealed resolving PE but edema and proteinuria remained unabated. Only two reports in children with SRNS on CsA developing PE could be identified,

Sudha Ekambaram

docsudha80@yahoo.co.in

1 Department of Pediatric Nephrology, Mehta Multispecialty Hospitals India Pvt Ltd, Chennai, Tamil Nadu 600017, India

2 Department of Pediatric Cardiology, Mehta Multispecialty Hospitals India Pvt Ltd, Chennai, Tamil Nadu, India

3 Department of Pediatric Pulmonology, Mehta Multispecialty Hospitals India Pvt Ltd, Chennai, Tamil Nadu, India but causal association is not proven [3, 4]. Early suspicion and withdrawal of the offending agent is the key. This case describes the need for a thorough history and a high index of suspicion for rare side effects of drugs used in SRNS.

Data Availability All data are transparent.

\section{Declarations}

Ethics Approval NA

Conflict of Interest None.

Consent to Participate Informed consent obtained.

Consent for Publication Informed consent obtained.

\section{References}

1. Adler Y, Charron P, Imazio M, et al; ESC Scientific Document Group. 2015 ESC guidelines for the diagnosis and management of pericardial diseases: the task force for the diagnosis and management of pericardial diseases of the European Society of Cardiology (ESC) endorsed by: the European Association for Cardio-Thoracic Surgery (EACTS). Eur Heart J. 2015;36(42):2921-64.

2. Hastillo A, Thompson JA, Lower RR, Szentpetery S, Hess ML. Cyclosporine-induced pericardial effusion after cardiac transplantation. Am J Cardiol. 1987;59:1220-3.

3. Kavaz A, Özçakar ZB, Karadeniz C, Tutar E, Yalçınkaya F. Pericardial tamponade in a child with nephrotic syndrome. Pediatr Nephrol. 2011;26:993-4.

4. Namdev S, Krishnamurthy S, Biswal N, Jagadisan B. Pericardial tamponade in nephrotic syndrome: an uncommon complication. Indian J Pediatr. 2013;80:598-600.

Publisher's Note Springer Nature remains neutral with regard to jurisdictional claims in published maps and institutional affiliations. 